\title{
Medical rituals and media rituals
}

KOME - An International Journal of Pure Communication Inquiry Volume 1 Issue 2 pp 64-80. (C) The Author(s) 2013 Reprints and Permission: kome@komejournal.com

Published by the Hungarian Communication Studies Assoiciation

\section{Zoltán Zsinkó-Szabó MD, MSc}

Dept. of Medical Anthropology, Institute of Behavioral Sciences, Semmelweis University, Budapest, Hungary

\begin{abstract}
In the present article the author examines the ritual elements of the professionalization during medical studies, and its interference with media content of medical significance, comparing the role of medical and media rituals on the way of becoming a doctor. It is to be explored how these medical soap operas, medical dramas, medical thrillers or crime stories do exert influence on medical identity and role expectations. Do medical students and their relatives (with medical expertise frequently) identify themselves with these roles? Is their way of reception critical or naïve? How media rituals are organizing, modulating the students' medical perception and expectations. Is there a mediated "shadow initiation" via media or it is excluded and denied? Does it perfuse the common social experience of becoming a doctor via peer communication and peer shaping of model behavior? We search the answers in the context of a theory of media rituals.
\end{abstract}

Keywords: medical initiation, professionalization, medical drama, media ritual, abject gaze, narrative analysis, bioethics teaching

The professionalization of medical students implies mixed sequences of students' rituals and overt and hidden elements of professional initiation. Teaching anatomy may also gain ritual importance transforming the relationship with the death, generating a shift in view of the human body by distancing, de-personalization of a former living person. Other rituals glorify the 'high tech' omnipotence of medical diagnostics and therapeutic intervention lending an empowering feeling of a new cyborg-like sensation of professional expertise. The medical rituals of the students on their initiation way have the same function as in other communities where rituals celebrate, maintain and renews the world in which one lives through their important social, psychological and symbolic dimensions. These rituals imply an 'aggregation of symbols', where symbols are 'storage units' into which the maximum amount of information is condensed (Turner 1969), this is because ritual symbols are 'multi-vocal', representing many things at the same time. Early results of O'Connors (1998) suggest the role model offered by medical drama like ER may influence medical students' perceptions 
and beliefs in a similar way to the real doctors they encounter. This concept is in line with Gerber's cultivation theory, which states that those spending more time with watching the world presented by television programs tend more to believe social reality portrayed on television causing a misperception of what is true in our world. (Cohen, Weimann 2000) As almost all medical students watch television medical dramas based on data of a systematic research (Czarny et al. 2008 ) and medical dramas can affect behavior change in the general public (Valente et al. 2007), we have to investigate their role in the "informal curriculum"of health care professionals regarding ethical and professional behavior issues in practice and in research as part of medical professionalization. Some of the researchers even propose, that

„students must be taught in a way that engages them and that does not ignore the potentially significant impact that cultural artifacts can have on their professional development and identity, while ensuring that their negotiation of popular culture gives them an authentic perception of the real medical world they are entering." (Weaver, Wilson 2011).

\section{On the methods}

In our research we carried out qualitative anthropological research with focus groups and deep interviews to explore the stages, types and elements of the process of medical initiation among former students and groups of medical students attending upper years and those at their preclinical years. Focus group work, deep interviews was completed by written reports regarding media consumption of medical dramas and soap operas in circle of students (as part of anthropological field work tasks in medical anthropological working group) at their preclinical period. The reflections on the influences of the medical dramas regarding medical professions were collected from recorded and written materials, and a narrative analysis in categorical-content perspective was made regarding the collected of these reports and anecdotes. The analysis of narratives and responses, focus group contents supported out working hypothesis that medical students go through many stages of initiations until they reach the formalized act of being conferred the degree of a doctor. Before medical school the object of their initiation may be an important event in childhood. That is, a serious illness in the family (maybe their own), hospital experience or the example of a physician relative, model of secondary school teacher etc. During university they list the experiences of the freshmen's camp, Hippocratic oath, some more serious illness. Passing or failing an exam may appear as an initiation stage but they all count the summer nursing practice after the freshman year (Becker 1961) as one. In the later years working on an ambulance, assisting in the operating theatre etc. function as initiations. One remarkable category we would like to draw attention to is personal example or model giving. 'Objects' (analytic psychological term) serving as models is an outstanding category regardless of situation, age, certain act etc. These initiators may condense almost all ingredients of a 'standard type initiation'. Initiators as model giving 'objects' may be significant members of the students' family, an outstanding secondary school teacher, seminar or practice lesson leader or the leader of a students' scientific circle. They all may serve for students as a lifelong 'compass', authentic pattern, during their personal and professional lives. In this paper we investigated whether media figures like Dr. House and other characters of medical dramas, soap operas and other medical media genres do offer such model giving an object or do not.

While we could trace out the contours of hidden ritual dramatic framework of student professionalization, there is another ritual space, which is also filled with medical content of ritual significance. This ritual space of medical content is part of the spectrum of media rituals. Biomedical soap operas, classic movies with medical themes, thrillers and horrors 
have a common function to look behind the curtain of the medical world. The medical dramas have some distinctive feature in the hidden curriculum ( ) : having a form of entertainment, 2) allows time for thought and reflection, 3) can be conducted on personal time, and 4) is nonthreatening as it relieves the viewer of being on the spot and needing to make actual decisions in the clinical environment. ( )

Less research is driven among medical students regarding the ritual function of these media content. Our hypothesis was that biomedical media contents are important "ritual" supplementary in transition towards becoming a doctor.

In our qualitative study implying focus group meetings and written material, we found that although our informants agreed that these medical series are fascinating, and may exert significant impact to turn lay people towards the clinical world, but these series lose their importance during the medical phase of professional initiation. Some the informant were receptive, while others proved to be critical regarding this series, nevertheless they could outline some functions and features of these genres.

Biomedical soap operas, classic movies with medical themes, thrillers and horrors have a common function to look behind the curtain of the medical world. Less research is driven among medical students regarding these media content. Our hypothesis was that biomedical media contents are important "ritual" supplementary in transition towards becoming a doctor. It is not surprising that both medical students and lay audience is led to the world of medicine and medical knowledge through the passage leading into spaces of anatomy and necropsy. In the case of the medical students it is the first years of anatomy with a hidden function of making distance towards corporeality, while in the case lay audience re-presentation of the dissected body celebrate the power of science and technology implying knowledge of forensic medicine.

In our qualitative study implying focus group meetings and written material, we had to realize that our informants were highly critical towards these series, nevertheless they could outline some functions and features of these genres.

\section{Medical drama as media ritual}

The medical dramas represent and mediate messages of a central ideological institution, the biomedicine in the ritual space of the media. As biomedicine implies key values of late modernity, its media representation offers surface for mirroring, performance, transformation and transfiguration with ritual functions of expression and renovation of the key values of modernity. This hidden function of the corpus of medical legends is associated with identityand community building function as well

If medical dramas and soap operas take part in symbolic construction and a dramatization of otherwise more or less hidden reality of clinical world, and its social experience with critical importance, then we may extend this ritual function beyond the circle of medical students towards lay public. (Lázár 2012) These stories and narratives working as legends of medical lifeworld, absorbing lay audience into this different reality, as a symbolic separation from their own lay world, immerse them into medical narratives of suffering, challenge, bodily catastrophes, fighting for the solution and healing or catharsis of the heroic failure. The hypnotic experience of watching this clinical world lets audience to leave the common role of being patient for empathic identification with the healer Dr Kildare, Dr House or the other clinical heroes. This may be seen as a sort of antistructure experience, which is followed by a deeper understanding of the healers, and a more reflexive relationship with the role and set of behavior of patients. This Turnerian view of medical media rituals as anti-structure 
presenting an alternative to the dominant hierarchical experience of clinical transactions in the society, helps to understand the resistance on the dominant medical side as well.

It is also true for medical dramas when they interrupt the former relationship between patient and healer, they empower the lay public, and de-mystify the close community of clinical world. This liminality drives audience as participant to see the clinical side in a different manner until returning to their own position after the story's end with a new experience reintegrated within the dominant frame of medical ideology. This ritual media experience may be even a harsh conflict with dominant medical ideology like in case of spiritualist medical soap operas like the Riget.

Both the media and the biomedicine are modern or late - modern cultural institutions sharing and/or competing for the mythical center in modernity. Both institutions enjoy a considerable approval and respect beyond the widespread critical voices, untrust and denial. There is also considerable symbiosis between the two as medical media dramas may strenghten medical insights and identification with clinical cosmology and medical narratives may create addict media consumption.

May be soap operas classified as media rituals? According to Carey even in media "news is not information, but drama. It does not describe the world but portrays an arena of dramatic forces and action; it exists solely in historical time; and it invites our participation on the basis of our assuming, often vicariously, social roles within it" (Császi cit. Carey 1989). That is also a strong argument to include medical drama and soap operas into the circle of media rituals like tabloids, talk shows, ceremonies or media scandals. As the ritualized function of news is mixed with entertainment, medical soap operas and medical dramas entertain with a hidden ritual participation by separation, transition ( or liminality) and re-incorporation during the watcher's ("mystic") participation via their semantic network. The medical dramas are more conventional in contrast with tabloids, talk shows and alike, and they tend to impose one dominant medical moral perspective. Victor Turner's understanding of rituals offers a key for us also, that these medical dramas as rituals embody and betoken transcendent values of late modern clinical cosmology.

\section{Professional identity and media}

Social theorists argue and emphasize the importance and function of media consumption in identity (Kellner 1995; Willis, 1990), where the basis of the construction of 'a narrative of self-identity' consists of mediated symbolic materials. According to Kellner in contemporary industrial society a 'media culture' has emerged which helps 'produce the fabric of everyday life shaping political views and social behavior, and providing the materials out of which people forge their very identities'. In this view of media determinism ,media stories and images provide the symbols, myths, and resources which help constitute a common culture for the majority of individuals in many parts of the world today. Media culture provides the materials to create identities whereby individuals insert themselves into contemporary techno-capitalist societies and which is producing a new form of global culture."(Kellner 1995) Medical contents in the media are thought to be useful in teaching biomedicine by improving communication skills (Wong et al 2009) and offering themes for Bioethics (Spike 2008) as well. According to Arawi (2010) teaching bioethics offer a framework to insert narratives of medical dramas into medical socialization, as a ,narrative genre that enhances emotional engagement, cognitive development, and moral imagination allowing for a more ethical sensitive student in training". According to her concept use of medical dramas can extend the present day practice based on case vignettes which do not allow discussants to see how the various stakeholders perceive and understand different events. The main difference 
is that the case studies in bioethics objectify patients and render them soulless while medical drama narratives objectify them to bring them to life.

However this enthusiasm may be controversial if we accept criticism of medical dramas blaming them for depicting the practice of medicine and bioethical issues in a strikingly realistic but sometimes inaccurate fashion. On this theoretical track we can understand, how values of bioreductionist techno-medicine is mediated by medical dramas like ER or House M.D.. On the one hand this frame of representation is part the homogenized and mediatized global culture, on the other hand these contents are re-shaped by 'subtle interplay of mediations' (Tomlinson 1991)

\section{Virtual corporeality of the Dead :}

If we try to apply the initiation pathway from anatomy, through analytic science via the clinical practice of diagnosis making and therapy and its drama even up to the spiritualization of the healing activity we can follow this sequence of topics and genres in the media rituals as well.

According to the neo-durkheimian framework of Cultural Studies the media embody the audience into his "virtual ritual community" of its disenchanted secularist values like monetarist orientation, high technology, materialist cosmology and political correctness, the cultural system of basic assumptions, values, rules and roles and imaginations. The legends of the "every night" criminal stories at 8 P.M. is about the fanatic and criminal behavior driven by fantasies of the wealth, and the heroic efforts of forensic experts helped by the high tech to uncover the truth through the analysis of alienated, reified informative corpse of the victim. This spectacle unifies two clinical insights- a medical student must acquire during his/her studies: one as part of alienation, and another one need for functional reification: - as the abject gaze with a focus on the physiological effects of death on the human body, where the abject nature of the corpse is mediated by the investigators' forensic gaze, which seeks to control crime, death, and abjection. This forensic gaze has ideological content being in pronounced association with displays of biological identification technologies.

In this sense popular media may take also part of the ritual process of becoming a doctor, as mass media is a mode of ritually enacting the shared understandings of a group.

James Carey (1998) helped us to reveal the ritual content of mass communication, where communication may be seen as ritual, with the aim of maintaining a culture or community over time. From the ritual perspective mass media with the above mentioned forensic medical content immersed into criminal context can serve re-enacting shared cultural understandings and cosmology of bioreductionist medical assumptions about the essence of human being and its materialist limitations, too.

As Simonson (2002) writes

"from stock dramas (science versus religion, technology run amok), to named practices ("professional wrongdoing," "breach of human rights"), to common roles (the reformer, the researcher, the innocent victim), - journalist" and our script writers of these NCIS, Bones, Dexter stories "draw upon and amplify existing conventions, and in so doing re-establish cultural and social norms."

Crime stories, -on one hand- remind us of the contemporary world's dangers, reinforce social standards by calling attention to deviations from them, but on the other hand- send message 
about the power of the technology and the institutions of criminal investigation and the forensic medicine within.

It is also interesting to put the representations of the human body into ritual and cosmological context This function is obvious in the case of medical students, who gain their first impressions about the human body through bones and dissected parts of the dead. But nowadays anatomy by its popular displays conquered museum, exhibition halls, with mixed aim of entertainment and health education with hidden function to express the hegemon view of human being as pure material, biologic -somatic entity encapsulated in new ideas about bodies are both formulated and contested as Stephens (2011) write. This renewed visual representation empowered by new visual technologies for public display and medical purposes is filled with culturally-determined metaphors where entertainment is mixed strongly with apologetics of late modern biotech. Doherty (2003) defines this genre as „forensic noir" mixing forensic science and "autopsy-driven entertainment, expressing a pronounced belief in the powers of forensic science to solve crimes and a morbid interest in human dissection. This is not far from the gaze of medical student where the lay, abject gaze of a medical student toward human cadaver is mitigated by the anatomical examiner's procedural entrance to the anatomical microcosm of a human being. This may have an initiation impulse parallel to the anatomical descensus of medical student towards the reified reality of lifeless human being. Abjection as an omnipresent threat to self-identity and subjectivity is expressed by Kristeva (1982), and it is a primordial element of medical initiation as well. For Kristeva, the corpse is the ultimate in abjection.The abject is ambiguous and does not respect borders and rules, and therefore, "disturbs identity, system, order"

According to Pierson (2010) C.S.I. constructs a multiplicity of gazes for viewers with a particular focus on the forensic and abject gazes along with the complex relationship that exists between them. This forensic gaze can be associated with the prevalence and proliferation of biological identification technologies in contemporary society.

The body centered framework is not the only way, as spiritualist framework represents the human body through symbolic anatomy of the chakra system, or Prana Nadi channels even new behavioral medicine generates different informational network representations which may embody social dynamics of the self through network of neuroimmunmodulation (Lázár 1994, 2005 On the other hand these criminal stories have wide socio-cultural and political connotative aura, where the abject and forensic gaze via the explorative work of C.S.I. investigators stares also the spaces and scapes of the whole society encaptured by criminal narratives filled with its hidden secrets and crimes.

As Pierson says: ,the forensic gaze also delves into the dark, inner cavities of the body in its quest for the legal truth." It is an analog way, how the healer is helped by autopsy, and medical student to get the proper knowledge.

This body-centered cultural focus may be seen also as hidden basic assumption of our culture. According to Foucault post-Enlightenment medicine is in its obsession with the improvement of the body, another objectifying the body, another inscription of power, another benevolent - or faux-benevolent-manifestation of the need to control, the same attitude is expressed by the way, how we deal with dying in the antiseptic anonymity of hospital rooms rather than in our own homes, which is considered to be "a technological blasphemy, a denial of the reality and dignity of death itself".

The representations of the dead body are quite different in the CSI: "CSI: Crime Scene Investigation" series and its „spin off" CSI (Miami, NY etc), the dramatic framework of which is anchored to scenes which take place in the autopsy suite. In CSI Miami we enjoy the computer graphics based animation of the explorative casual logic while gold, green, yellow 
colors of the sacralized iconography of the rich upper middle class, and its Americal lifestyle in the tropical leisure zone generate visual metacommunication and contrast to the ascetic scientific pursuit the Truth.

The success among media audiences led to organize even a wandering international CSI exhibition Series with an interactive website, (http://budapest.csiexhibit.com/index.html) and very pervasive visual promotion.
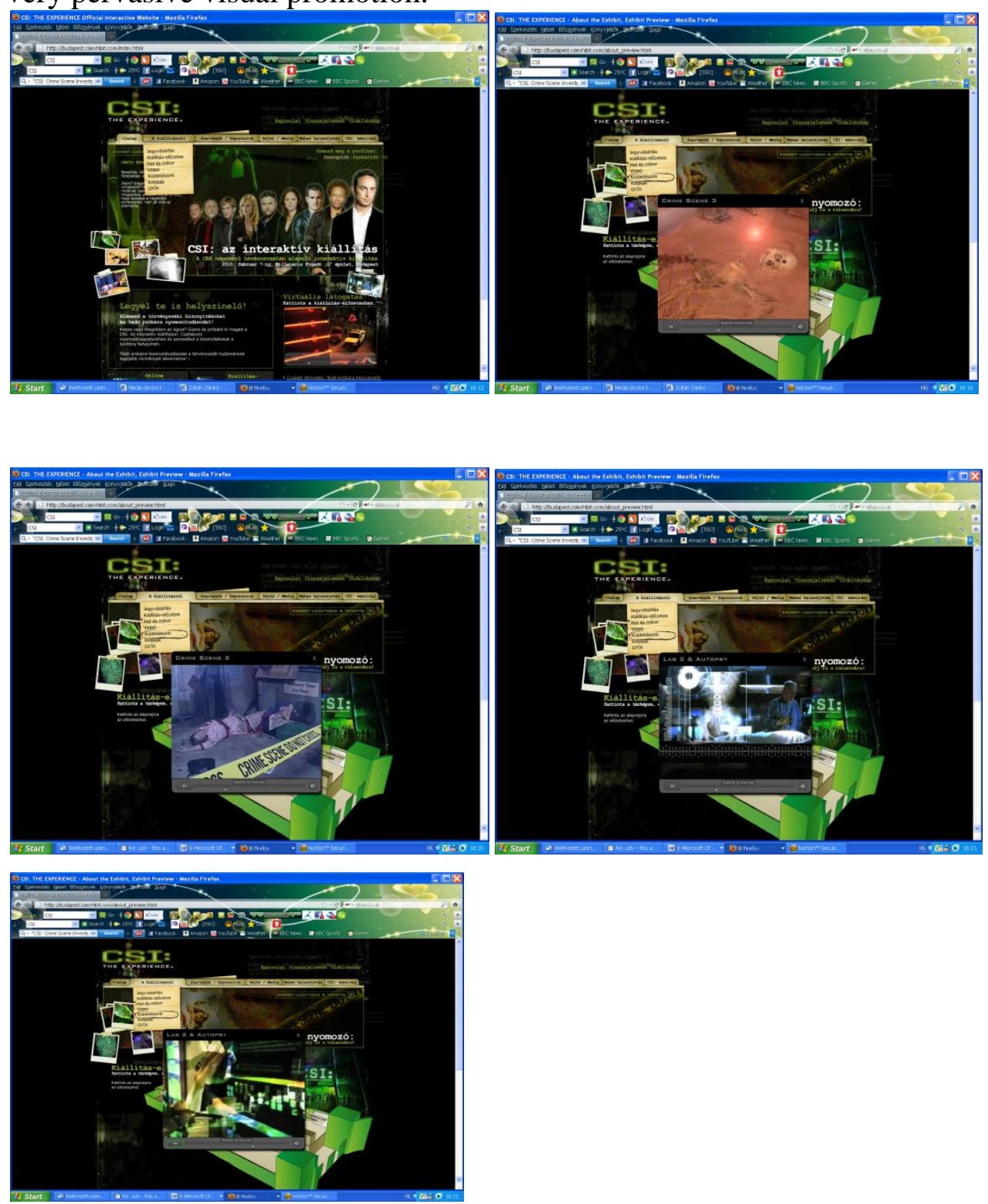

This web- ,iconostase" of CSI cult, offer a rich web of meaning, which is not far from our informants mentality. The new - almost religious identity is based on the facts, evidence based knowledge and the visually performed and celebrated scientific technology. As Tait (2006) writes „These sequences elaborate a modernist imaginary: the anatomized body as a vehicle for discourses of science and pleasure extends regimes of representation and looking inaugurated in the Renaissance dissection theatre." It offers a special analogy with anatomical theaters as Sawday shows us 'The anatomy theatre was a register of civic importance, an index of the intellectual advancement of the community, and advertisement 
for a city's flourishing cultural and artistic life' (1995), the CSI series celebrate the high tech scientificated body with its victimized past narrative immersed in criminal context. The Forensic milieu became a central scene for this media-ritual show of the body in a mixed scientific and criminal context presenting the honor and dignity of science, technology, criminal investigation and law. Series like SCI spin offs, 'Dr. Bone', 'Waking the Dead', 'Cold Squad', 'Cold Case' put in focus this temporary asylum between life and dissolution, criminal enigmas and the final Truth. Pathology is a niche for events of secularized, materialized Bardo, and this way it is strictly religious surface between covered narratives of human ontologies immersed into suffering and success motivated by money, carrier and selfrealization. The personal and inflated calvaries are encoded in a histological, biochemical, biophysical sign system explorable by high-tech. This carnographical shift of ontological representation of the Human being at the edge of non-existence has more than philosophical and hermeneutical content, it points clearly to the present crisis of the bio - reductionist notion of the Human being. The Human being as a victim only occasion for technology to fulfil its supreme power, the facts are only substrates of complex system of data analysis and re-presentation. As this carnographic semiosis unfolds not only human, but Transhuman dimensions too, knowledge society dates forensic pathology in the prime time zone to celebrate design, high tech computer graphics, multimedia iconic intertextuality. The camera generates another multidimensionality using different registers for the narrative presence with the high-color depth of CSI Miami for example, the documentative past via "home videolike" documentarist recording and the computer-based hyperreal representation of the scientific truth. Low, middle and higher realities, the unfolded past, the reflecting present and the special time of analysis which is anchored to the signs of past, happening in the presence and determines, or controls the future. These are the dimensions where the leader of cult guides the audience.

The good old shamanic trance returns, spirits of high tech machinery whisper the truth via CSI masters to the hypnotized listening audience of the media ritual. The scientific control and the technological narcissism are the message.

\begin{abstract}
„Digital identifiers appear on the screen to make the correspondence between the cumulated images. In effect this sequence depicts a simple assemblage of clues, but in the hands of the CSI this evidence is translated and displayed via high-tech signifiers. The problematics of photographic truth are elided and instead this augmentation with technology and the expertise through which it is deployed extends a panoptic gaze which enables science to succeed where policing and the manipulations of lawyers fail" (Tait 2006)
\end{abstract}

We used the term "carnography" referring to an obsession with the human body that "suggests a connection between horror and pornography, nevertheless we debate Tait's thesis regarding the necrophilic gaze, where "science offers a refuge for the pornography of death." As she argues, the audience is ,positioned to take pleasure from imagery of death, imagery which often penetrates the flesh" (Tait 2006) continuing Pinedo's statement about both pornography and horror that 'expose what is normally concealed or encased to reveal the hidden recesses of the body, porn through carnal knowledge and horror through carnage' (Pinedo, 1997), where digitally produced shots simulating these hidden recesses of the underskin bodily world and the effects of violence upon them generating „examples of this 'carnographic' revelation".. The fact is that these carnographic scenes - making science exciting, and spectable -are media rituals celebrating science and high tech, where human actors are just necessary substrates of the industry, an industry which produce homogeneous series like CSI spin offs and its auxiliaries: web site, wandering exhibitions etc. The colors, 
the characters, the schemas of dramatic framework, the narrative trajectory: all of these components are standardized, like in the McDonalds. These media rituals are regular mass media masses of high tech, professionalism, globalized standards with one word - the control. And the control is the most important category of stress theory, management of catastrophes and corporations, enterprises, states and local communities of all sizes.

This layer reflects the core, inner layer of the (medical) culture with the undercurrent of implicit basic cultural assumptions and worldviews about the suffering Human with its limited bodily, materialist essence and corporeality without its spiritual content and perspectives. These interpretations embodied in rules, narratives and discourse just like anatomical lessons are about the scientific and technological culture's norms and values with their visible elements.

\section{Multiple scopes of clinical world}

There is also another layer with importance regarding the medical professionalization, which is about the medical reality woven from transactions, displayed by characters, role, dramas and narratives.

The medical dramas conquered media space step by step. The first "swallows" like medical series like Dr Kildare preceded this "clinical boom" with decades and one must mention an American sample also: the City Hospital serial which was broadcast from 1951- to 1953 and another one from England in the late fifties and sixties, the Emergency Ward, which had been broadcasting for ten years . (This long "show time" was repeated by later the medical drama "House M.D." with its 8 eight year story and two Golden Globe prizes.)

This early sample differed much, as they were more realistic, the medical script was worked out with moral messages, while the clinical enigmas, decision "turmoils" were not exaggerated at all. According to Karpf the medical profession was reluctant for a long while to see either the media or the public meddle in what it took to be its province. "Broadcasting to an 'undifferentiated audience' would only distress the frail and neurotic; hypochondria might result" (Karpf 1988) In the early period media functioned as mediator of scientific facts and knowledge like in the case of the BBC program Your Life In Their Hands, which started in 1958, provided opportunities for the scientific and technological perspective to gain ascendancy in health-related coverage. The next decades brought with the rise of consumerism and the patient's view a more skeptical audience attitude towards the medical contents where the dominant position of the doctor seemed to have waned. In this more pluralistic environment new ways of portraying medicine and health care emerged, and instead of the classical heroic 'good doctor' image a more realistic, or sometimes very controversial spectrum of medical figures emerged in clinical dramas and medical soap operas. On the other hand beyond a sort of inflation of traditional moral superheroes of clinical world, a new scape of collaborative team competence emerged, and we can accept Gabe's statement (1974), that in this big picture "The representation of health and medicine as essentially technical issues effectively reinforced the individualistic approach to health, offering a 'dominant ideology' suggesting that health and medicine were essentially about pharmaceutical and technical progress." This accurate mediation of real medical facts became blurred in the contemporary medical media scene for sake of entertaintment. As Carlyle writes about the recent Renaissance of medical drama, these cognitive dramatic framework is perfumed with a sort of mystery, when things are transformed into their enigmatic frame not fully explained. "Programs like ER and Casualty are at times deliberately obscure, drawing the audience into a blur of activity where instructions are half 
heard, decisions are fudged and things don't always work out for the best." Although this way of representation is usually denied by the medical expert audience, the naïve watcher and medical students may be involved in this atmosphere without distancing, also. Collee's criticism is about this fascinating mystification:" The fact that we don't understand the medical process makes us more appreciative of its complexity. The chaos and the jargon engage us intellectually in trying to work out what's happening. The moral ambiguity adds richness and depth while enabling us to put our own interpretation on events." Although close cooperation helps writers, producers, and medical advisers ensuring higher level of accuracy with a sort of medical censorship, nevertheless the audience immersed into these media space so deeply and totally that there is a danger that television being watched gains public health concern related with health behaviour covered or miscovered in these fantastic and usually dramatically distorted stories and the same distorsions may emerge in the medical roles and model behaviors, cognitive schemas, like in the problematic issue of Dr. House or the strange and sexually overheated milieu of Gray's Anatomy .

There is another genre, those thrillers and horrors, where narrative is immersed in the world of medical students like Rusowitzky's thriller Anatomy I and II. , where the medical students in the University of Heidelberg form a secret "anti-Hypocrates' society for forbidden anatomic research on living peers in an atmosphere of post-Nazi secret societies, with fanatism of scientific suprahumanism, which included polymeric preparation in living bodies for a better technical achievement. Our student informants did not find it interesting at all, rather dull, while others were seriously embarrassed by the stupid story. The similar denial was expressed in the case of Flatliners made by Joel Schumacher.

The students of the focus group session were more accepted in the case ER and the other medical soap operas like House M.D.:

„I was a real fan of ER. I am a little bit older than my schoolmates, my generation liked ER much. Although my foster-father told me, that the ER's screenplay was ridicule. There is no such thing, that the medical staff run up and down shouting and jumping through cables and wires in Autoservice-like hall. Nobody operates beyond curtains in a passage, but we liked it very much." Now my young colleagues are watching House M.D., and this traffic jam like dramatic framework has been disposed to the routes of medical decisions."

But those parents who worked as medical doctors were generally very critical.:

"I was also an ER fan, and watching the series my mom, being also medical doctor was very disappointed telling: No, no, not that way. Why do they give epinephrine, this is not so,, that must be done in a different way." From that interest moment I started to see it through a more critical lens, sometimes saying that it is really rubbish. But ER was an almost documentary compared to House M.D. and the Grays Anatomy, these series are really irreal."

This case represents sample of a multidimensional space of professional socialization, with conflict of informal authority and mediatized patterns of medical knowledge. But other soap operas have bad reception on the side of the students, like Gray's Anatomy "filled with strange sexual atmosphere, and stupid dialogues."

Other opinions point to the fascinating function of the medical milieu in these series, it is not about medicine, the world of doctors and nurses are only mean to recruit watchers, curious regarding the secret medical world. But they also deny the rigid "professional dignity," the "I am proud to be a good doctor" feeling. They find it very embarrassing, that there is an 
exaggerated sexual climate in Gray's Anatomy, because - looking at these series - " a belief may emerge that the things are going this way in our hospitals to".

Let's see some samples from the focus group statements regarding these soap operas.

"There is a sort of inflation of medical soap operas, all of which has a title beginning with Dr. this or that, Bone, Donor etc." This transplantation story impressed me, I mean not the story, but its end... The story was about an old man with a progressive neurological disease. After his injury, there was a conflict between him and his daughter, as he wanted to give his organs to other patients, being in a fatal, final stage. I felt compassion, so these stories may bring strong bioethical messages, which may be useful in teaching medical communication and bioethics." One can find other normative messages with wider relevance. like the medical expertise, when the script writer uses the medical role and prestige to draw a model behavior of a committed, devoted, hyper-effective expert, who behaves like a self-sacrificing intellectual slave working without a break except few moments of holiday events to pronounce the exceptionality of these days. This picture of working night and day, the icons of the heroes of ER, sleeping in their clothes, with books on the bed." "The other sample, the special Sherlock Holmes like icon of Dr House is also about the legitimation of expertise which overvalue the anomalies of his character."

The students classified the medical serials, as medical dramas (House M.D., ER), medical comedies (Scrubs), medical soap operas (Gray's Anatomy) and medical crime stories, thrillers and horrors (like SCI clones, Bones, Riget - Kingdom Hospital, Coma, Anatomy I II). The medical dramas exerted the most significant influence in the premedical, pre graduate period- although no one told that these movies played a decisive part in choosing medical profession. Other informants mentioned that among their friends - one learning economy at the Corvinus University- reported that 'House M.D.' was fascinating and getting him to think about change towards medical studies. These informants depicted the medical world as a fascinating and heroic one. Other opinion emphasizes that the medical world is like a microcosm offers a model for a wide scale of human behaviors, attitudes and transactions. Medical anthropologists like Cecil Helman also describe hospitals as a common frame of diverse institutional metaphor like church, city, factory, market and alike. It is not surprising that clinical worlds offer wide space for the human social microcosm of soap operas.

The medical soap operas like 'Gray's Anatomy', 'Die Schwartzwaldklinik', or the Czechoslovakian 'Nemocnice na kraji města' ('Hospital at the End of the City') were rather about human relationship, interactions and melodramatic events of the local medical community and its collisions and relationship with the outer world.

A different genre is the category of medical comedy like 'The Scrubs' or the Hungarian cartoon 'Please, The Next', - 'Kérem a következöt' with their sarcastic and ironic, caricature -like figures and dramatic framework.

The other important idea - emerging from these students' reflections-, was a sort of Sherlock Holmes idiom, the similarity or analogy between detective work and medical diagnosis and decision making.

Another classification implied three different levels: focus on the profession (ER), focus on the professional ('House M.D.'), and focus on the non-professional interactions in the professional milieu ('Gray's Anatomy'). One student said that this sequence of stages reflects her phases towards medical profession also. 
The reports contained a sort of schism in the perception of the world of medical dramas, as they kept their reliability only until the students gained clinical experiences. The insight of the real clinical world cause dissatisfaction and tension, the same attitude, what their parents with medical background expressed.

These genres were exploring the causes in a sharp dramatic manner or decision making plays created the thematic focus like in the case of 'House M.D.', or the CSI forensic serials. Collecting the students' reports about the influence of soap operas and medical dramas, we could circumscribe a minority group who attributed importance looking at the ER serial in their childhood to choose the medical profession. Two of the informants mentioned a Hungarian cartoon about Dr Bubo and the nurse Ursula, and their adventures, a medicalAesopus-like collection of fables from of the mid seventies repeated several times later in the late nineties. A student told, that it had gotten her to cut and operate her toy animals one by one and these doctor role playing was her favorite childhood game. It is hard to deny this influence in choosing the road to become a doctor.

Some students mentioned - as a desirable model - 'House M.D'. as an elective seminar in the Marburg Medical School. They cited the cardiologist Jürgen Schafer, who used 'House M.D.' episodes regularly as part of teaching.

In the secular, disenchanted and bureaucratic social space the biomedicine may take some parts of the former religious control of everyday life. Where somatic health is in the place of salvation and beatitude and lapses of health behavior may replace the sin, and doctor is the moral authority instead of the clerk, media és medicine both generate a ritual space, a secular quasi-church. Medical soap operas like modern "legends of saints" are teaching narratives about the somatically good or bad and the their social, technological and psychological secularist context.

The biomedicine plays a great part in determining what is good or bad, normal and abnormal, how can we control insecurity and misfortune. The body weight, eating habits, body figure and its standards, all they are elements of this normative picture of reality guarded by medical expertise, evidence based knowledge machinery, and health industrial developments, high technological extensions.

We realize that biomedical soap operas offer a permanent media liturgy or masses of medicinal biopower and control. Two ritual space in one package- media rituals and medical rituals. Media church represents the church of medicine, church of health with a hidden legitimating and advertising rethorics on side, and a critical controlling role which may cause loss of trust in biomedicine. The audience may experience a double "participation mystique".

Some other thoughts from the focus group session:

"Although we don't like these series, there are some medical students who seem to be addict of these series, looking at different genres, like a whole spectrum of medical courses. 'Bones' from Forensic Medicine and Pathology, Dr. House is a course of medical decision science. Otherwise Dr House is really close relative of Sherlock Holmes, drug addict, eccentric and deviant hero., who is genial, creative problem solver with very conflicting social background. A course of work-life balance, or workfamily conflict - as sort of medical sociology and sexology:' The Gray's Anatomy' just like the medical history of socialist Central- East European medical lifeworld, "Hospital at the End of the City',', or its Bavarian counterpart,' Die Schwartzwaldklinik'.

"We can mention a different genre, where the medical narrative is covered and mixed with other files of the story, like the Neighbours with doctor Magenheim. This is even a more intimate insight to the doctors ' world from the home perspective." 
"Really it may help to build up a fantasy of a medical life career, as the behavior, the emotions and experiences represented by Dr. Magenheim would easily be internalized. There is no horror, there is no closed expert world of medical doctors, therefore the model and the figure of the doctor gets closer and closer, and more sympathetic. It can be also part of a hidden emotional initiation mediated by media."

"Die Schwartzwaldklinik' offers similar "gemütlich" milieu, but in an aristocratic and idyllic context with high medical prestige and elegant doctors. It is totally different compared to the sterile, abstract technocratic American medical professionals. The narrative of the Schwartzwald Clinic is sentimental, like a Hungarian movie from the thirties, the chief doctor and the nurse,"

"These stories have feminist connotation, like in this case, where the nurse starts medical studies for the sake of their romantic relationships."

"There are important Hungarian "art Kino" with relevant message regarding the humanist or non-humanist sides of biomedicine, like Gaál's 'Sodrásban', or the 'Oldás és kötés' of Jancsó Miklós, or 'The Lost Paradise', a Sarkadi novel adaptation by Makk Károly. These movies may help professional socialization as much as other influences."

"The Institute of Behavioral Sciences used to organize 'Filmklub' but these movies are about psychiatric, thanatological, sociological or bioethical problems and themes. Now they organized a whole series of Marco Ferreri in a monthly scheduling."

The last theme of the focus group was challenging, because the students brought up media as source of counter- ritual of classic bioreductionist assumptions and the cosmology of biomedicine. These assumptions exclusive materialism, organ-centered, analytic orientation, upward causation and alike are subverted by some movie narratives, like in case of Wenders' 'Der Himmel über Berlin' ('Wings of Desire') or its American remake, the 'City of Angels', or the extreme 'Riget' by Lars von Thiers and its remake, Kingdom Hospital by Stephen King. These movies are part of the western cultural trend, which can be called Occulture or Re-enchantment (Partridge 2002).

"A good sample is the heroine of the movie "City of Angels, who is seduced by an angel played by Cage, and we can compassionately follow how she developed from a skeptical surgeon or cardiologist, or whatever into a spiritual novice, partner of an angel with open spiritual eyes, a mystic who dies suddenly after this transformation. The German version was much deeper, but rather for few..."

"In these lines of genre one can mention the Prophecy Trilogy or Pentalogy, where the prosecutor is the key figure at the frontier of the facts and evidences and the transcendental reality facing the morphology of the Suprahuman".

This way the room for autopsies, the place where the somatic evidences are dominant becomes a passage from here to there over the transcendental septum. And a whole Hospital may be transformed to be the home and the battlefield of the spirits, like in the case of the right.

But these transits are also legitimate in the world of multiple medical realities (Johannessen, Lázár 2006), as these spiritualist explanatory models are not absurd in the cosmologies of alternative medicine. 
The results of narrative analysis in categorical-content perspective

\begin{tabular}{|c|c|c|}
\hline Principal sentences & Category & Comments \\
\hline $\begin{array}{l}\text { ER realistic, authentic with general } \\
\text { medical role model, while Dr House } \\
\text { irreal, fantastic, the controversial figure is } \\
\text { charismatic, popular for lay people, } \\
\text { finally Gray's Anatomy as a real soap } \\
\text { opera represents an interpersonal } \\
\text { relationship of surgeon community in } \\
\text { front. They are complementary }\end{array}$ & Medical genres & $\begin{array}{l}\text { The informants tipologize the medical dramas } \\
\text { and medical soap operas along genre features, } \\
\text { narratives and characters. }\end{array}$ \\
\hline $\begin{array}{l}\text { Media narratives show doctors as heroes, } \\
\text { The mediatized clinical world is fascinating, } \\
\text { and exerts recruiting effects }\end{array}$ & $\begin{array}{l}\text { Lay cluster. } \\
\text { Influence of medical dramas on friends } \\
\text { and other lay people }\end{array}$ & Esoterism of clinical life world is fascinating, \\
\hline $\begin{array}{l}\text { "... more than half of my schoolmates } \\
\text { watched medical dramas in elementary } \\
\text { school, and the situation did not change } \\
\text { much in the secondary grammar school. }\end{array}$ & & popular \\
\hline $\begin{array}{l}\text { My lawyer friend followed every part of the } \\
\text { Gray's Anatomy for years, without missing } \\
\text { an episode, she was interested much in the } \\
\text { hidden world of clinical community, and - } \\
\text { although her mother worked in a hospital. } \\
\text { She was happy to be supported not become } \\
\text { a doctor. }\end{array}$ & & $\begin{array}{l}\text { even for those who otherwise have health } \\
\text { worker's relatives or wanted to be }\end{array}$ \\
\hline $\begin{array}{l}\text { A young solicitor lady told, that she watches } \\
\text { medical dramas because of nostalgy (she } \\
\text { wanted to be medical doctor in an earlier } \\
\text { period), but now she is glad to avoid } \\
\text { medical route, as .based on these medical } \\
\text { dramas- (they don't have leisure time, work } \\
\text { to much, etc) }\end{array}$ & & or denied to be medical doctor \\
\hline $\begin{array}{l}\text { The lay informant emphasized that this } \\
\text { foreign clinical world is different from ours, } \\
\text { and he reported mistakes, and obvious } \\
\text { paradoxons. }\end{array}$ & & $\begin{array}{l}\text { The western clinical world is usually } \\
\text { compared and differed from the own clinical } \\
\text { reality }\end{array}$ \\
\hline $\begin{array}{l}\text { Another lay informant told, that Dr House } \\
\text { was unsympathic, and because of this she } \\
\text { ceased to watch the serial the foreign } \\
\text { medical dramas shows a contrast. }\end{array}$ & & $\begin{array}{l}\text { Characters may be basis for denial of the } \\
\text { serial.. }\end{array}$ \\
\hline $\begin{array}{l}\text { "As I suffered a lot because of diseases in my } \\
\text { childhood and medical world was familiar to } \\
\text { me, I liked much medical drama on TV like } \\
\text { ER, influencing my doctoral games and my } \\
\text { intent to be a doctor" }\end{array}$ & Childhood memories cluster & $\begin{array}{l}\text { Medical dramas exert influence on early } \\
\text { decisions on to be a doctor, }\end{array}$ \\
\hline $\begin{array}{l}\text { "I was attracted by Dr House as an assertive } \\
\text { superman with clinical omnipotence, } \\
\text { although suffering from character problems }\end{array}$ & & Medical expertise is fascinating. \\
\hline $\begin{array}{l}\text { "I liked House M.D. very much, based on my } \\
\text { primitive biological knowledge the story } \\
\text { seemed to be without any mistakes, and I } \\
\text { thought it had given insight to the medical } \\
\text { world, I think it helped me to choose medical }\end{array}$ & & $\begin{array}{l}\text { Medical dramas exerts fascination influence } \\
\text { in teenager period also. }\end{array}$ \\
\hline
\end{tabular}




\begin{tabular}{|c|c|c|}
\hline $\begin{array}{l}\text { profession" as a teenager I loved to see House } \\
\text { M.D., I found it very interesting. }\end{array}$ & & \\
\hline $\begin{array}{l}\text { My mother who is a medical doctor, told: } \\
\text { "No, this not, why do the give } \\
\text { epinephrine, this is not that way, that thing } \\
\text { mustn't be done "and I accepted her } \\
\text { viewpoint and started to see it with more } \\
\text { criticism as a teenager I like the soap } \\
\text { opera, Grays's Anatomy. }\end{array}$ & Expert relatives cluster & $\begin{array}{l}\text { Medical expertise creates critical or denying } \\
\text { attitude towards medical dramas. }\end{array}$ \\
\hline $\begin{array}{l}\text { They let Hungarian doctors get insight in } \\
\text { the clinical world of richer western } \\
\text { countries but many mistakes from } \\
\text { translation disturb expert watchers } \\
\text { My friend's mother as a health worker told } \\
\text { that the illnesses in House M.D. are really } \\
\text { existing, but they are rare }\end{array}$ & & $\begin{array}{l}\text { Lay elements like translation may hurt } \\
\text { medical credibility. } \\
\text { The medical content is not reliable. }\end{array}$ \\
\hline $\begin{array}{l}\text { House M.D. annoyes me now . } \\
\text { Gray's Anatomy is ridiculous, I just laugh at } \\
\text { it now }\end{array}$ & $\begin{array}{l}\text { Medical students with } \\
\text { expert identification }\end{array}$ & $\begin{array}{l}\text { A medical student at the late phase of } \\
\text { professionalization becomes critical, and } \\
\text { distancing. }\end{array}$ \\
\hline $\begin{array}{l}\text { Medical soap operas may confuse the } \\
\text { patients if they represent non-realistic } \\
\text { elements. }\end{array}$ & & $\begin{array}{l}\text { They show responsibility for lay public's } \\
\text { disinformation and distorted expectancies } \\
\text { through the media. }\end{array}$ \\
\hline $\begin{array}{l}\text { "As the time passed by, I was filled with } \\
\text { doubt regarding House M.D.'s figure, as I } \\
\text { learned to involve patients into the clinical, } \\
\text { where healing must include body and soul } \\
\text { at the same time. }\end{array}$ & & $\begin{array}{l}\text { Based on bio-psycho-social basis they criticize } \\
\text { bioreductionist and technomedical ideology of } \\
\text { medical media serials. }\end{array}$ \\
\hline $\begin{array}{l}\text { "...a medical student was very critical } \\
\text { with these medical drama because of their } \\
\text { non-realistic issues, there are diseases, } \\
\text { nonsense representations, and absurd } \\
\text { dynamics of illness courses }\end{array}$ & & Strong clinical reality testing \\
\hline $\begin{array}{l}\text { I have used to see ER since age } 5 \text {, and it } \\
\text { exerted influence on my becoming medical } \\
\text { student, it was a dynamic landscape of my } \\
\text { future, an aim to fight for, the serial helped } \\
\text { me to tolerate to see blood, wounds and } \\
\text { clinical scapes. }\end{array}$ & Socialization cluster & $\begin{array}{l}\text { Medical dramas exerts positive influence on } \\
\text { medical socialization in the early, pregradual } \\
\text { period. }\end{array}$ \\
\hline $\begin{array}{l}\text { These medical dramas helped me to choose } \\
\text { the medical profession, as they show an } \\
\text { idealized clinical world and roles in it }\end{array}$ & & \\
\hline 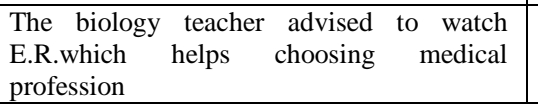 & & \\
\hline
\end{tabular}

\section{Summary}

Although medical dramas, soap operas are not classic media rituals in their Neo-Durkheiman sense compared to talk shows, one can find several elements of a secular "mystic participation" sharing the key assumptions, basic moral values, behavioral rules, roles and models of our late modernist (post-postmodern), high tech and hyperrational age. Even the criminal series like CSI serials - called a special genre,,forensic noir" mixing forensic science and "autopsy-driven entertainment"- may be treated as analogy of early anatomy experiences 
of medical initiation. The medical context offers a fascinating archetype-like frame for adoration of professionalism. The psychopathic personal limitations in the case of House M.D., or anomic sexual behavioral chaos in Gray's Anatomy are only a background - where the Gestalt of medical professionalism and the power of high tech medical industry comes to the front.

That is why it is tempting to insert the medical media rituals into the ritual spectrum of medical initiation. Our informants agreed regarding the fascinating nature of medical themes and genres, and showed slight ambitendence regarding their determinative role in choosing medical profession accepting the pregradual influence in inducing interest towards the profession. Some of the informants reported a sort of alienation from these media contents after their real clinical experiences. Other students started to search for medical mistakes, being more critical, usually without success. They developed the same professional superiority regarding these media representations as their parents with medical background. These opinions draw a slight but strict border between the institutional socialization and media effects, whatever fascinating and influencing they are. This shift can be explored during the process of medical professionalization, when students report the multimodal media influence of medical dramas, and the denial of their strict role in professionalization at the same time, supporting the view that the media as the dominant representational aspect of modern culture is overwritten by the embodied and 'lived experience' of (professional) culture in medical socialization. Warde (1996) argues the need to consider other sources of cultural experience beyond media influences like identification with occupational groups not dependent upon shared patterns of commercial consumption. The production view of the professional self underestimates the social context of identity formation, and overemphasizes the role of media outputs at the expense of the variety of practices which create and sustain social relations of the professional clinical life world.

Some reports (Spike 2008, White 2008, Arawi 2010, Weaver R., Wilson I. 2011, ) signified the importance of bioethics education practice incorporating medical dramas like House M.D. episodes, nevertheless students did not mention these media contents as a source of valid medical knowledge in bioethical, medical communication or sociological context. On the other hand there is equivocal and sounded opinion that these medical soap operas, medical dramas, or medical thrillers or crime stories do exert influence of medical identity and role expectations in premedical years and among lay public. It is the task of the future to get a more detailed picture how media rituals are organizing, modulating lay public's medical perception and expectations. Although it is generally denied, we can't exclude these "medical media rituals" as shadow part of medical initiation .

\section{REFERENCES}

Arawi Th. (2010) Using medical drama to teach biomedical ethics to medical students Medical Teacher 2010; 32: $205-210$

Bury M, Gabe J. (1974) Television and medicine. medical dominance or trial by media in eds. Jonathan Gabe,David Kelleher,Gareth Williams Challenging Medicine London: Routledge

Collee J (1999) Medical fiction BMJ. 1999 April 10; 318(7189): 955-956

Carey J.(1998) Ritual communication: From everyday conversation to mediated ceremony. Rothenbuhler, E. W. Thousand Oaks, CA: Sage.

Cohen, J. \& Weimann, G. (2000). "Cultivation Revisited: Some Genres Have Some Effects on Some Viewers". Communication Reports, 13(2), 99. 
Császi L. (2010)Broadening the Concept of Media Rituals: Tabloids as "Low Holidays of Television" EastBound http://eastbound.eu/site_media/pdf/EB2010_Csaszi.pdf

Czarny, M. J. Faden R.R. Nolan M.T. Bodensiek E., Sugarman J. (2008) Medical and Nursing Students'Television Viewing Habits: Potential Implications for Bioethics The American Journal of Bioethics, 8(12): $1-8,2008$

Doherty, T. (2003). Cultural studies and "Forensic Noir." Chronicle of Higher Education, 50(9), 15-16.

Kellner, D. (1995) Media Culture: Cultural Studies, Identity Politics Between the Modern and the Postmodern. London: Routledge.

Lázár I. (2012) Az egészségügy szervezeti antropológiája in Orvosi Antropológia eds.: Lázár I. Pikó B. Medicina Budapest

Lázár I. (1994) Social-psychoimmunology (Szociálpszichoimmunológia Kand. tézis) MTA

Sawday J. (1995) The Body Emblazoned: Dissection and the Human Body in Renaissance Culture Routledge

Johannessen, H., Lázár I. eds. (2006): Multiple Medical Realities. Patients and Healers in Biomedical, Alternative and Traditional Medicine. Oxford, New York, Berghahn

Karpf A. (1988) Doctoring the Media London Routledge

Kristeva, J. (1982). Powers of horror: An essay on abjection. (L. S. Roudiez, Trans.). New York: Columbia University Press.

O'Connor MM (1998) The role of the television drama ER in medical student life: Entertainment or socialization? JAMA 1998, 280:854-855.

Partridge Ch. (2002) The Re-Enchantment of the West: Volume 1 Alternative Spiritualities, Sacralization, Popular Culture and Occulture T\&T Clark International

Pierson DP: (2010) Evidential Bodies: The Forensic and Abject Gazes in C.S.I.: Crime Scene Investigation Journal of Communication Inquiry 34: 184

Pinedo, Isabel Cristina (1997) Recreational Terror: Women and the Pleasures of Horror Film Viewing Suny Series, Interruptions: Border Testimony \& Critical Discourse

Simonson, Peter (2002) "Bioethics and the Rituals of Media," Hastings Center Report 32, no. 1: 32-39:

Spike J(2008) Television viewing and ethical reasoning: Why watching Scrubs does a better job than most bioethics classes. The American Journal of Bioethics 8(12):11-13.

Tait S. (2006) Autoptic vision and the necrophilic imaginary in CSI International Journal of Cultural Studies 1 : 45-62

Tomlinson, J. (1991) Cultural Imperialism. London: Pinter Publishers.

Valente, T. W., Murphy, S., Huang, G., Gusek, J., Greene, J., and Beck,V. 2007. Evaluating a minor storyline on ER about teen obesity, hypertension, and 5 A day. Journal of Health Communication 12(6): 551-566.

Warde, A. (1996) 'Afterword: The Future of the Sociology of Consumption', pp. 302-12 in S. Edgell, K. Hetherington and A. Warde (eds) Consumption Matters. Oxford: Blackwell/The Sociological Review.

Weaver R., Wilson I. (2011) Australian medical students' perceptions of professionalism and ethics in medical television programs BMC Medical Education 2011, 11:50

White G. B. (2008)Capturing the Ethics Education Value of Television Medical Dramas The American Journal of Bioethics December, Volume 8, Number 12, 
Wong R, Saber S, Ma I, Roberts JM (2009) Using television shows to teach communication skills in internal medicine residency. BMC Medical Education 2009, 9:9. 